\title{
FÓSSEIS: MATERIAL DIDÁTICO DE FOSSILIZAÇÃO PARA ALUNOS COM DEFICIÊNCIA VISUAL OU BAIXA VISÃO
}

\author{
Ana Clara Silva Araújo할 Marcela Oliveira de Sousa²; Vanessa Cardoso Pereira ${ }^{3}$; Eulália
} Letícia Silva Souza ${ }^{4}$; Adriana Ferreira de Sousa ${ }^{5}$.

\section{INTRODUÇÃO}

Este relato trata da construção de um material didático como proposta avaliativa da disciplina Instrumentação para o Ensino Fundamental, do curso de Licenciatura em Ciências Biológicas, do Instituto Federal do Piauí - IFPI. Teve como objetivo melhorar a aprendizagem, a partir de um método de ensino mais acessível e diferenciado que despertasse o interesse dos alunos, considerando os eixos delegados pelas orientadoras a partir dos PCN's - especificamente o eixo terra e universo - com base na análise de livros didáticos para a o ciclo requerido ( $6^{\circ}$ ano), no qual se definiu o conteúdo: Os tipos de fossilização.

O material proposto buscou também a promoção do ensino e aprendizagem de alunos com deficiência visual (cegueira) ou baixa visão, promovendo uma aprendizagem do conteúdo através de uma atividade lúdica e no qual o professor que se apropriar desta metodologia poderá utilizar-se da interdisciplinaridade de conteúdos e mesmo de disciplinas, por demonstrem o assunto com um material multidisciplinar e inclusivo. Elencando as disciplinas de Ciências e Geografia, explorando os conteúdos tais como: fóssil; processos de fossilização; terra primitiva; origem e evolução da terra. As pessoas com deficiência frequentemente ficam segregados, escondidos, ou a parte no processo de escolarização. Ao se tornar um espaço de inclusão, a escola promove trocas enriquecedoras para toda a equipe escolar, incluindo os alunos e suas famílias. A fonte de informações mais importante para o educador traçar sua diretriz de ação junto ao educando é saber como ele é (como percebe, age, pensa, fala e sente). $\mathrm{O}$ aluno com deficiência visual percebe a realidade que está a sua volta por meio de seu corpo, na sua maneira própria de ter contato com o mundo que o cerca. Partindo dos próprios caminhos perceptuais destes sujeitos, o educador pode oferecer-lhes oportunidades para entrarem em contato com novos objetos, pessoas e situações e, assim, saber (ou aprender).

\footnotetext{
${ }^{1}$ Discente em Licenciatura em Ciências Biológicas do IFPI/ Campus Teresina Central. E-mail: anaclara17c@gmail.com

${ }^{2}$ Discente em Licenciatura em Ciências Biológicas do IFPI/ Campus Teresina Central. E-mail: marcelaoss24@gmail.com

3 Discente em Licenciatura em Ciências Biológicas do IFPI/ Campus Teresina Central. E-mail: vanessaa.card@gmail.com

4 Discente em Licenciatura em Ciências Biológicas do IFPI/ Campus Teresina Central. E-mail: eulalialeticia267@gmail.com

5 Docente em Licenciatura em Ciências Biológicas do IFPI/ Campus Teresina Central. E-mail: adrianafs27@ gmail.com
} 
Nesse sentido, Caiado (2007) afirma que o papel do professor, no processo de inclusão educacional do aluno cego, é de mediador do saber a partir da organização de atividades dos estágios sensório-motor e pré-operacional, visando à discriminação sensorial e o desenvolvimento global, ou seja, movimento, percepção, memória e conduta, relatando-se a importância do treino dos demais sentidos como compensação da ausência da visão.

\begin{abstract}
Assim, no treino do tato, da audição, do olfato, a criança cega poderá experienciar o mundo que a cerca e formar ideias sobre esse mundo, ou seja, pela estimulação dos sentidos remanescentes, com exercícios repetitivos e cada vez mais apurados, a criança vivencia o real, explorando os objetos e deles extraindo informações que ativam estruturas cognitivas inatas (CAIADO, 2007, p. 228).
\end{abstract}

No que se refere ao ensino de Ciências, mostra-se dificuldade de trabalhar algumas temáticas dentro do ensino de ciências dentre eles a Paleontologia. Isso se deve à dificuldade e, muitas vezes, à falta de conhecimentos específicos, metodologias diferenciadas e materiais didáticos que aproximem os educandos de temas que não raro tornam-se abstratos pela forma como são abordados em sala de aula. Assim, mesmo a Paleontologia sendo uma ciência importante para se compreender num sentido amplo as temáticas geológicas, biológicas e ambientais, existe pouca divulgação desses conteúdos para os estudantes do ensino fundamental e médio. Neves, Campos e Simões (2008) acrescentam que as informações paleontológicas que tanto alunos como professores possuem são oriundas dos meios de comunicação influenciados pelas imagens veiculadas na mídia. Tais veículos com frequência abordam esses temas de maneira inadequada e/ou reducionista, restringindo essa ciência tão abrangente aos dinossauros. Isso minimiza o seu papel crucial no entendimento da origem e evolução da vida na Terra. E quando falamos de abordagens específicas e uma metodologia voltada para alunos com necessidades específicas percebeu um déficit ainda maior.

\title{
RELATO DE EXPERIÊNCIA
}

A princípio determinamos o público alvo em que seria trabalhado a atividade, o tema foi escolhido com base na análise dos livros didáticos da mesma coleção. Em seguida, definimos realizar a atividade para alunos do $6^{\circ}$ ano do ensino fundamental, e pesquisamos os tipos de deficiências em que iríamos trabalhar o tema. A proposta da atividade se deu por meio de um sorteio de temas eixos no qual iríamos trabalhar e nosso tema sorteado foi: Terra e Universo.

O objetivo do trabalho era levar aos alunos uma maior compreensão acerca do tema que seria trabalhado através de materiais táteis que os fizessem instigar a imaginação e 
construir o conhecimento com o suporte da exposição oral e manuseio dos recursos táteis. Promovendo a participação dos alunos com dificuldades visuais. A atividade foi um teste que pudesse perceber como os alunos reagiriam diante da utilização do recurso didático, jogo molde/contramolde para melhor desempenho de aprendizado.

O material foi exposto sobre uma mesa na qual os alunos se aproximaram e em uma espécie de jogo da memória os mesmos, com a ajuda apenas das mãos, tentaram descobrir qual peça se encaixa a outra em uma forma de molde e contramolde. Ao final da atividade foi possível observar o esperado para ambos os públicos, a dificuldade por parte dos alunos sem deficiência na identificação de algumas peças que possuíam muitos detalhes de tamanho pequeno, por não terem a sensibilidade tátil que é mais "aguçada" nos deficientes visuais que como esperado, apresentaram facilidade em executar a atividade.

Imagem 1: peças do jogo processo de fossilização.

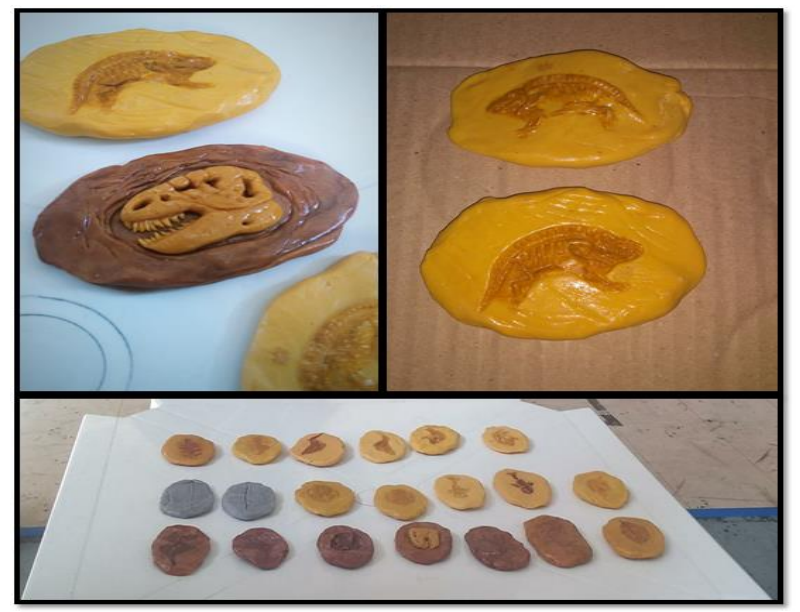

Fonte: própria

\section{CONSIDERAÇÕES}

O trabalho proposto foi uma experiência de grande aprendizado, além da produção intelectual pensando num produto didático para melhorar o ensino, foi também um momento de construção de um material inclusivo para alunos com deficiência visual, com a temática de fossilização presente nas redes de ensino. $\mathrm{O}$ ensino de ciências permite a utilização de uma gama de estratégias investigativas e experienciais, que transcende ao tradicional teoricismo. Desse modo, há maior fluidez na aprendizagem uma vez que o contato, a experiência do aluno com o material permite-lhe significar e construir os conceitos abordados nos conteúdos, de forma concreta real. Esta amplitude de métodos e mecanismo para dinamizar o ensino de ciências mostra que, em seu processo de formação, o professor deve estar em constante aperfeiçoamento, seja por meio de formação continuada ou mesmo pesquisando e inteirandose acerca de novas metodologias e abordagens de ensino. 
O material didático proporcionou aos alunos com necessidades visuais uma aprendizagem significativa acerca do tema fossilização, de modo que ele por meio do tato significa conceitos abstratos (como moldagem e contramoldagem) até então apenas dialogados. Sendo uma metodologia que possa ser aplicada/desenvolvida nos diversos níveis de ensino, e que fosse uma opção dos professores de ciências ao abordarem tal temática, sempre com o intuito de diversificar e ampliar os estímulos no aluno que proporcionem sua aprendizagem.

\section{REFERÊNCIAS}

CAIADO, Kátia Regina Moreno. Cegueira: concepções de aprendizagem e de ensino. Revista Brasileira de Educação Especial. V. 8, n. 2, 2007.

GIL, Marta. (org.). Deficiência Visual. Brasília: MEC. Secretaria de Educação a Distância, 2000. 80 p.: il. - (Cadernos da TV Escola. 1. ISSN 1518-4692)

LOPES, M. da G. Jogos na Educação: criar, fazer e jogar. São Paulo: Cortez, 2001.

NEVES, Jacqueline Peixoto; CAMPOS, Luciana Maria Lunardi; SIMÕES, Marcello Guimarães. Jogos como recurso didático para o ensino de conceitos paleontológicos básicos aos estudantes do ensino fundamental. Terra Plural, n. 2, p. 103-114, 2008. 